\title{
Networking, Exclusion and Negotiated Visibility: Feminist and Anti-Racist Social Media Debaters' Endurance Strategies
}

\author{
Sofia Larsson* \\ * PhD Student. Department of Arts, Communication and Education, Luleå University of Technology, Sweden.
}

Abstract

\begin{abstract}
Since the rise of the Internet, there has been a growing interest in research on its implications for democracy and participation. This article contributes to the research on online citizen political participation with a bottomup, grassroots perspective that focuses on non-professional and individual actors. Through interviews with 15 young Swedish bloggers and social media debaters involved in feminist, anti-racist and leftist politics, the present article explores the conditions for citizen participation, as well as the benefits and impediments to being a blogger and social media debater. The conclusion is that while engaged citizens focused on feminism and anti-racism have many negative experiences, strategies enabled by social media use give them access to a support system that is fundamental to their endurance. The challenges for feminists and women online seem to be the same as those present at the beginning of the 1990s, but strategies for coping and resisting are now enabled by new tools. The participants in this study depend on their network for collaboration, safety, dissemination of content, support, and a sense of community, which is facilitated by the use of information and communication technologies for collaboration and dissemination.
\end{abstract}

Keywords: civic engagement, political participation, social media, bloggers, feminists

\section{Introduction}

This article ties in to research on political blogs and online activism, and adds a grassroots perspective from a Swedish feminist and anti-racist sphere that is engaged in the use of the Internet and social media. In particular, the article is connected to research on the challenges women and feminists face when participating online, and the strategies they use to endure in the online political sphere. Online citizen participation has been studied from many perspectives dating back to the early days of the Internet. The Internet has been discussed as having great potential for political underdogs (Papacharissi, 2001), as well as for allowing more voices to be heard (Gillmor, 2004). From the time the very first online discussions were hosted on the Internet, however, researchers studying online communication (e.g., Herring, 1993; 1996) were already finding that women faced serious challenges in open groups, such as flaming and trolling.

This article contributes to the branches of research on online engagement that are based on a citizen and everyday perspective and that focus on democratic online discussions. The participants in this study are the sort of online citizen actors that earlier Internet researchers studied in hopes of observing more opportunities for excluded or marginalized voices. More specifically, this article adds to the research on women's and feminists' Internet and social media experiences in terms of political participation and online discussion. Furthermore, it contributes a perspective from a Nordic country; Nordic countries often occupy top positions in rankings for freedom of speech, gender equality, and Internet usage and access. As such, the article initiates a discussion about the true challenges of an online democratic public arena in places with high levels of equality, Internet access and skilled users. The analysis builds on empirical material from interviews conducted between 2013 and 
2014 with citizens participating on social media. This article presents research based on qualitative data that have been analyzed using a material-focused approach. It makes use of theory and research concerning the Internet and participation in a general sense, but also make use of knowledge from research on online relations and women's experiences of online abuse.

The overarching research questions that have guided the article are:

What are the major challenges and opportunities social media debaters experience in their online participation, and what strategies do they use to endure?

\section{Online political participation}

When studying the potential and challenges for engaged individuals participating as active citizens in society using the Internet, there is a large body of work from which to draw. One major branch of this research explores the implications of social media use in formal settings such as political party campaigns and elections (Vaccari, 2008; Johnson \& Perlmutter, 2010), or for participation and political involvement in general (Kushin \& Yamamoto, 2010; Towner, 2011; Boulianne, 2015). Another branch of research focuses on individual involvement that takes place in non-formal settings in civil society, such as studies that look at online social movements, activism, resistance, and group mobilization (e.g., Olsson, 2008; Shaw, 2012; Nielsen, 2011; Bennett \& Segerberg, 2012; Shaw, 2013) or more everyday forms of participation such as Bakardjieva's description of subactivism (2009; 2010): "politics that unfolds at the level of subjective experience and is submerged in the flow of everyday life" (2009, p. 92). A further area of research studies the use of the Internet as a public sphere, assessing, for example, its potential and challenges as a tool for democratic discussion (Hagemann, 2002; Zhou, Chan, \& Peng, 2008; Wojcieszak \& Mutz, 2009; Loveland \& Popescu, 2011; Ruiz et al., 2011; Mummery \& Rodan, 2013). The specific challenges of online communication for engaged women-sometimes labeled online abuse-is yet another field of inquiry that focuses on the power relations of grassroots and excluded voices online (Herring, 1993; 1994; 1996; 1999; Herring, Johnson \& DiBenedetto 1995; Herring, Job-Sluder, Scheckler \& Barab, 2002; Keller, 2012; Shaw, 2012; 2013; Jane, 2014a; 2014b; Vitis \& Gilmour, 2017; Lewis, Rowe \& Wiper et. al., 2017). This paper is connected to the research on informal settings with an everyday or grassroots perspective. Research focused on managing communities and trolls also offers insights (Binns, 2010; Abidin, 2013; Zamith \& Lewis, 2014).

\section{Women online}

Computer-mediated communication via the Internet has long been a subject of research, predating the Web. This area of study has included observations on how users behave in forums and other online settings (e.g., studies on flaming and trolling). According to Herring (1996), however, gender perspectives on these topics emerged later. She studied online communications in 1991, and found "eye-opening differences in the ways 
men and women interact" (1996, p. 1). Herring argued that women and men in discussion groups had different styles and communicative ethics. According to her, the female style was characterized by supportiveness, while the male style was characterized by adversariality. Needless to say, this conclusion implies consequences for an equal public discourse.

One early theory of online behavior and communication was that online forums and similar text-based tools that lacked some central property of vocal or face-to-face interaction would filter out social cues such as gender and race, and that this might contribute to redistributing social power and balancing opportunities (Baym, 2010, p. 54). Herring however, disputed this vision of more equal discussions online by showing that men dominated many online forums. Herring (1996) found that communication was gendered, and that men wrote more often and in a more adversarial style; she summarized this finding as "women thank and men flame." Male- and female-dominated discussion groups thus developed different cultures, and each gender seemed to lean toward one communication style. Herring furthermore underscored that it was the overall social culture that was the real issue behind flaming and online abuse. Others also emphasized that flaming occurs because of norms, not as a result of a lack of them (Baym, 2010, p.59), and that these norms develop in forums just as in the rest of society. If (as this particular theory suggested), the medium steered the ethics toward flaming, women would flame more online as well; this was not the case, however, in Herring's studies (Herring, 1994, p. 291). Herring also suggested that no change will occur in online discussion cultures as long as we live in a society that values and accepts a certain kind of ethics: "as long as men dominate the Internet and the ideology of anarchic debate continues to be valorized and codified into behavioral norms, we are likely to be singed by flames in cyberspace for some time to come" (1994, p. 292). Herring (1999) further found that resisting online harassment can be difficult due to the dominating culture (often libertarian in nature), in which free speech ideology on the Internet clashes with (female) communicative ethics. There is thus research that supports the idea that there can be different communicative styles in different settings, and that there are gender differences in communication (such as Herring, 1994; 1996; Baym 2010). It is reasonable to depart from the assumption that communication online is shaped by "larger social forces," such as gender and culture, and that these influences mediated interactions (Baym, 2010, p. 66).

Therefore, aspects that impede online communication, such as harsh language, trolling-defined by Herring et al. (2002) as "luring others into pointless and time-consuming discussions"-incivility, misogyny, racism, hate speech and threats of sexualized violence/e-bile (Jane, 2014b) are common problems that have consequences. Megarry's (2014) study, for example, showed that abusive comments on Twitter caused women to modify their behavior, both on the street and on the Internet, and online sexual harassment has been said to impede online participation (Gumbus \& Meglich, 2013 p. 48). Furthermore, women seem more upset by sexualized threats of violence than men, and report about it differently (Jane, 2014b p. 536).

The strategies used by women to counter or manage uncivil or abusive messages are diverse. In a study that focused on blogs, Abidin (2013) found that two of the five "coping mechanisms" for commercial bloggers were designed to manage haters by either ignoring or publicly shaming them. Vitis and Gilmour (2017) described ways to manage harassment online, such as avoidance, withdrawal, testimony, and resistance. Other researchers found that sexual harassment could also be managed by changing one's online name, or decreasing Internet 
use (Gumbus \& Meglich, 2013, p. 48). Jane (2014b) highlights the ways in which online abuse impedes participation, and says that its effects on women have been neglected in the research community. She argues that "on-line hostility is getting more prevalent, it is getting uglier, and it has a number of distinctly gendered characteristics" (Jane, 2014b p. 534) (threats of violence and rape included), and she contends that this "e-bile" can be conceptualized as textual sadism that is directed to one or more people in the form of texts or images that cause pain. In particular, she argues that this e-bile causes women to withdraw from the online public sphere. Jane also highlighted how women were feeling unsafe and having anxiety and began censoring themselves, turned off their comments, etc.

Vitis and Gilmour (2017) studied the use of Instagram as a tool to resist and expose online sexual abuse on Tinder and OKCupid, with strategies that they described as "creative resistance which is critical, comedic and entertaining." They described how the instagrammer documents harassment, resists, engages, and also punishes perpetrators; she draws "unflattering, 'sad-naked' portraits" of those who were offensive, and thus is "objectifying back." Death threats, however, were not countered at all.

Research by Herring et al. (2002) on a feminist online community targeted by a "troll" attempting to disrupt found the following responses to trolling: banning, ignoring, refuting, negotiating with, and insulting. Furthermore, these researchers proposed solutions to trolling such as filters, educating users, developing policies in groups, and understanding trolling and its motives. Countering the abuse is not always easy, however, and can be challenged by prevailing online norms, such as accusations of censorship aimed at moderators. Women's strategies of countering harassment by means of exclusion are often seen as censorship, and Herring et. al. claim that the ideological norms of (male-gendered) libertarianism dominate on the Internet. Herring et. al. study specifically underlines what happens when inexperienced forum users encounter trolling, and what happens when ideals of openness clash with the need for safety from abuse and trolls. For example, in their study they found a communitarian/libertarian conflict, as the libertarian sees an Internet without rules, and the communitarian prioritizes the common good. Also, liberal and radical orientation conflicted in the forum they studied, as the former encourages women to step out into the public sphere, while the latter acknowledges isolation as a strategy. The prevailing online norms guide the women (in the forum) on how to manage trolls. Should one ignore trolls, or reason with them for the sake of securing total inclusion? Or should one ban trolls and create safe spaces for the violated group? Herring et al. (2002) concluded that the community they studied failed to counter the trolls due to these conflicting ideals and a false belief in reasoning with someone who seeks only to deceive. The challenges were summarized as balancing ideals of inclusion and safety, and the study showed the difficulties of managing trolling and highlighted its silencing effect on a feminist forum.

With a similar focus on trolling, Shaw (2013) explored the responses of a network of female bloggers to the silencing practices (harassment and trolling) of trolls, and found that resistance practices were collectively developed within the network. In this interview-based study Shaw does not ask how silencing works, but rather focuses on the way it doesn't work when feminist bloggers resist these silencing practices. Moderating is one practice that was developed to counteract the silencing practices of trolls. Shaw describes strict moderation as a successful tactic, yet playing with the trolls such as changing their spelling to make them look ridiculous was another strategy that was used. Leaving the hateful posts out there for all to see rather than deleting them, or 
drawing attention to trolls or a Twitter account were also mentioned. In a similar approach, Megarry (2014) studied content tagged by a Twitter hashtag. The women use the hashtag as a space to write about how men who use abusive comments on Twitter impede their participation. The abuse cause them to modify their behavior, both on the street and on the Internet. In her 2014 study, Megarry also highlighted the strategy of exposing the online sexual abuse for others to see. Vitis and Gilmour's (2017) study of online sexual harassment also found strategies of resistance in the instagrammer's use of satire and shame in the exposing of perpetrators. It seems that objectifying and trolling back can make women feel less like victims.

\section{Online relations and visibility}

Since the end of the twentieth century, some have theorized that we now live in a network society (Castells, 1996), with society organized based on loose connections in which Internet technology plays an important role. Wellman et al. (2003) used the concept of networked individualism, which refers to society being based on "loosely bounded networks" rather than group or local solidarities. According to this framework, networked societies and technology offer new opportunities for political participation. Participating in social media and blogs offers the possibility of finding likeminded people, and for publishing and mobilizing to challenge the existing dominant discourses. The concepts of networks and communities can also be used to describe social organization online - the virtual counterpart of the "real" world offline. Baym (2010) offers a thorough account of how to theorize online groups and personal connections as networks or communities. Online networks differ greatly from older forms of online forums in that they are not based on a shared community or group membership. Social network sites are an example of such networks, with the individual at the center rather than the community. Baym (2010, p. 90) calls these sites egocentric, and everyone has their own personalized content and individuals might not have access to the same people or messages. Networks constitute groups only if the members of different people's social networks overlap. Compared with an online community, there is probably less of a "sense of shared space" in the network environment, and fewer shared norms, practices and group identities. Online communities, in contrast, are described by Baym as groups that have boundaries. Online communities are often understood relative to the idea of a real community in society. Baym argues that certain qualities can be found in online communities, and that some are necessary in order for a website to be defined as a community rather than merely a platform $(2010$, p. 74$)$ or social networking site. The following five qualities (2010, p. 73) are considered relevant to both online and offline community definitions: shared space, shared practices, shared identities, support for members, and interpersonal relationships. Online communities seldom share the same geographical location, but can occupy virtual spaces such as websites or online visual environments. Shared practices in online settings could be, for example, a certain way of communicating, the presence of insider jargon, or the existence of behavioral norms within the community. Online communities can also offer support, comfort, and the exchange of resources. Furthermore, the sharing of identities can manifest itself as a shared idea of "we." Online groups also enable people to build interpersonal one-on-one relationships. Dahlgren (2011) discussed a new privatized political practice: "From the networked and often mobile enclosures 
of this personalized space, the individual engages with a vast variety of contexts in the outside world" (2011, p. 104). He described a trend of moving into a "solo-sphere," in which political engagement has "the tendency toward isolated, individualized communication." In this online political context, Dahlgren (2011) also argued that visibility is a key parameter to consider in understanding citizens' online participation. Visibility (understood as "being in the public") is essential for an engaged citizen using social media to be able to participate, find likeminded others, and influence the debate. However, Dahlgren also acknowledged the negative aspects of public visibility, such as the sense of surveillance.

\section{Method and Material}

This article is based on in-depth interviews with 15 feminist and anti-racist bloggers and social media debaters. The interviewees were between 21 and 38 years of age (mean age 27), and they included 2 men and 13 women. Most of the participants were recruited through the blogosphere and the Twitter-sphere. They wrote on the topics of feminism, anti-racism and leftist politics, with the first two topics dominating. The approach was to some extent emergent; for example, was some interviewees selected after interviews with the first participants had already begun (Merriam, 2009, p. 169). Emergent methods provide a sensitive and flexible strategy that allows for adaption throughout the course of the research project (Ritchie \& Lewis, 2003, p. 4). There are many ways to find bloggers and engaged citizens in social media, such as through portals, ranking sites or indexes. Not all bloggers and debaters, however, were included on the available portals and indexes. Thus, the most suitable approach was a purposeful selection method involving a thorough scanning of the blogosphere, Twittersphere and Facebook-sphere within the topics of choice. First, a group of participants was found by scanning the sphere and going through indexes and a smaller part of participants was then found through the first group of participants who agreed to the interview (a snowball selection principle). The participants were contacted using e-mail or via the social media site on which they were active. The selection criterion was based on age and social media use in order to find younger debaters who used blogs or social media. The aim was to interview both those who had succeeded in reaching a great number of readers/followers, and those who had recently begun engaging or who had a small number of readers. Some participants had thousands of readers on their blogs every day or thousands of Twitter-followers or members/followers on their Facebook group or page, whereas others had between twenty and several hundred daily blog readers. Because the participants were dispersed across Sweden, the interviews were conducted via Skype or telephone. The final material consisted of 190 pages of transcribed interviews. 


\section{Results}

\section{The Participants and Their Goals}

The group of participants can be described as feminist, leftist and anti-racist, and the interviews suggest that the majority primarily write about feminism in combination with leftist politics and anti-racist views. About half of the interviewees were members of a political party, and two-thirds were also active in civil society as members of an association. They were not paid professionals, and were not active on social media as official representatives of any political party, even though the roles are difficult to separate, and some had ambitions to become more professional political debaters or bloggers. The participants used a very diverse and interconnected mix of social media platforms on a daily basis (Larsson \& Olsson, 2016). For example, one participant with a considerable media toolkit for political purposes is an engaged citizen who uses a Facebook page, Instagram, a blog, a collaborative blog, Facebook, and Twitter. In terms of background, most participants began with either a non-political or political blog. The personal blog-either a classic "diary" blog or a blog focused on a specific topic (e.g., popular culture, music, makeup and fashion)-was a typical starting point for many of the bloggers. These blogs then developed into more political blogs. Meeting others online, however, could result in being "recruited" by larger collaborative blogs or web projects. A second group started blogging with a political purpose from the very beginning, discussing topics such as feminism, racism, and leftist politics. It was, however, difficult for some to specify precisely when their blogs became more about politics than other topics. Furthermore, small-scale participation through commenting on others' blogs and participating in discussions on online forums are part of their early development as bloggers, and can be important steps leading to participating in public debate as a citizen. For some individuals, lifestyle blogging, commenting, and writing online are thus part of their journey toward more political engagement and collaboration.

The participants described the audience they sought to reach with their social media engagement in terms of reaching the likeminded, the broad public and their opponents, and reaching the likeminded was highlighted the most. Thus, their primary aim was not to reach the general public, politicians or mainstream media. The interviewees described the likeminded as those who were either more "knowledgeable" or merely "interested" in those topics. There was an obvious desire to participate in discussions with other debaters who were wellinformed and well-read on a theoretical level. Their aim in this context was to provide readers with a deeper theoretical analysis. As a result, they directed their texts to those who were already participating in the debate, or sought to reach individuals who were already knowledgeable about these topics. A top feminist blogger described a space reserved for feminists, where isolation from the opposition was also an important strategy. The audience who they see as merely "interested" in the topics of feminism, anti-racism and leftist politics are considered to be ordinary people or young people who think about these issues. Following citations are examples of thougts about the audience, given by two interviewees.

I think that it is mostly those who are already feminists who read my blog but want to know more about it. I think that I have a theoretically heavy blog and what I do above all 
is to radicalize people who are already engaged in feminism.

We try to strive to make feminism not an entirely academic subject because it is really important that it doesn't become something only scholars or gender studies students discuss behind closed doors in seminars. Instead, it should be broken down into something simple and easy to explain to the broad public who has no interest in studying at the university.

A few bloggers, however, were interested in reaching those who were less familiar with their topics-the broad public-and, specifically, those who might become, for example, feminists, and were exploring the subject. This interest was explained by the desire to include more than students of gender studies in the debate. Accordingly, there was little interest in writing to opponents, with only a few bloggers hoping to bring new perspectives to this group, since opponents were not the main target audience for their texts. Consequently, their writing was largely part of discussions within their own sphere, but, significantly, they also aimed to offer a body of knowledge to those who were more or less likeminded in order to provide support for their arguments and ideas. This approach can also be interpreted as more excluding than including; the bloggers mostly sought to offer new angles and perspectives to the public, but their public was generally limited to sympathizers or those already showing an interest in the topic. Some mentioned that they would not be politically active if it were not for the blog and social media. Their issues with traditional political party participation were diverse; such participation was perceived as difficult to initiate, too male-dominated, or not suited to their radical opinions. Furthermore, the typical activities of in-person meetings, rallies, and door-to-door campaigning do not appeal to everyone.

\section{Challenges of citizen engagement in social media}

In terms of challenges, the main themes that emerged were visibility and negative experiences in online discussions. These two themes were intertwined, and the analysis also revealed the conflict between democratic visibility and social intervisibility, as suggested by Dahlgren (2011, p. 99). The negative experiences that they described related to abuse and to a culture of low tolerance within their sphere. In relation to visibility, participants attempted to explain why they were open or not open with their identities. 
Figure 1: Themes related to the challenges of online visibility

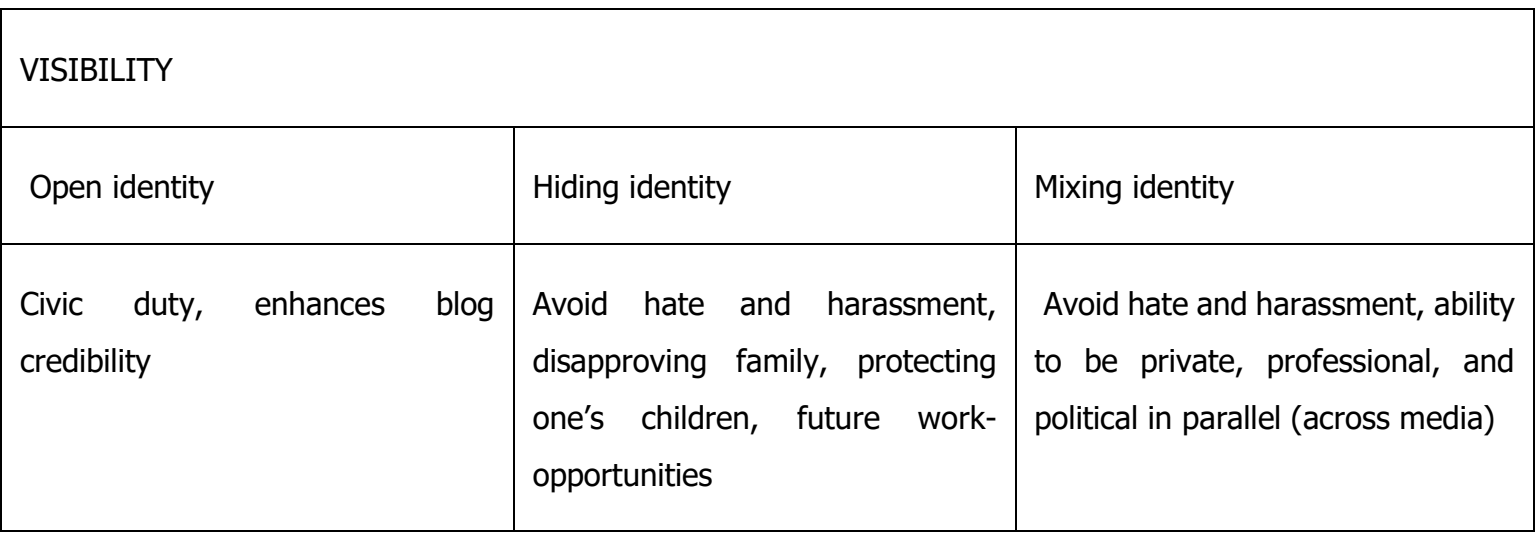

Despite the drawbacks, many had made the conscious choice to be open about their identity based on feelings of civic duty or issues related to blog quality. For example, a commitment to the anti-racist struggle was deemed too important for the author to remain anonymous, with the reasoning that "I'll be affected by racists whether I speak up in my name or not." This issue of openness had also led participants to adapt their online lives in various ways, such as publishing less personal content or avoiding anti-racism topics-which some described as the most risky topics-altogether. Thus, blogging about private and personal matters, opinions, and feelings made these engaged citizens feel more vulnerable.

It might be cowardly in a way to not take on the big discussions because we want to spare ourselves from the hate. But at the same time... everyone contributes in some way, and we feel that there are so many that take on the big issues and live under death threats, so... it is very selfish to think like this actually... but then, well, WE do not have to do it.

The interviewees perceived many risks from being open about their identities, and referred to problems related to disapproving relatives, work opportunities, and impacts on their children or on their businesses as selfemployed individuals. On the other hand, they also mentioned that it would be less motivating to blog or write anonymously.

Hiding one's identity was another subtheme. Being open about their identities was clearly problematic for various reasons, and, consequently, one strategy was to hide their identities in various ways. The reason for hiding one's identity was primarily the threats received from hateful people, racists and misogynists. To manage such threats, participants either used an alias, or simply excluded their surname or first name; a less open identity made it easier to dare to participate. Another reason for hiding was that a participant's political identity might clash with other identities, such as a professional or private identity. Being a political and perhaps radical leftist or feminist might provoke family members, and might also be considered inappropriate within a future profession. The result of this inner negotiation can thus be a less open identity in combination with restraint in expressing radical opinions online. 
The theme of mixing identities relates to the similar challenge of adapting to the online media landscape and the visibility that is sought even though it causes problems. In an earlier article a collegue and I (Larsson \& Olsson, 2016) studied these interviewees' media toolboxes for citizen engagement and found that they adapt their identity in different media and so manage their visibility. That research also led us to conclude that blogs, Twitter, and Facebook groups and pages were used for more political purposes, and offered a public or political space, whereas private Facebook accounts (including job relations, family, friends etc) required negotiation between identities and restraint in political terms. Facebook is a space for gathering many relationships and, therefore, some individuals minimize their political identity in their writing. When switching between many different media, engaged citizens may thus find their private, professional and political identities in conflict. In terms of visibility and identity, the engaged citizens found that abuse was the most common problem, although the feeling of being watched or "googled" was also a restraining factor. Consequently, as described above, many adapted their social media identities to balance the private, public, professional and political characteristics of their writing. There were, however, other strategies for managing abuse aside from managing one's identity and visibility.

Figure 2: Themes related to managing abuse

\begin{tabular}{|l|l|}
\hline \multicolumn{2}{|l|}{ ABUSE } \\
\hline Proactive managing & Reactive managing \\
\hline $\begin{array}{l}\text { Cooperate to avoid or to monitor abusers, } \\
\text { publish policies and commenting rules on blog, self- } \\
\text { censoring }\end{array}$ & $\begin{array}{l}\text { Moderating, deleting, blocking/excluding, brief response, } \\
\text { ignoring, mocking, mobilizing friends to counter }\end{array}$ \\
\hline
\end{tabular}

Abuse is a widely discussed problem associated with political participation online, and many interviewees had experienced hate, personal insults, sexist verbal attacks, or ridicule. The worst abuse, however rare, was death threats that were received in e-mails, in discussion threads, and sometimes made indirectly in other online spaces. This risk of abuse impeded bloggers and prevented them from using e-mail and enabling comments on their blogs. One notion expressed by the interviewees was that they do not have any obligation to supply a space for these opponents at the cost of their community. The challenge of abuse was managed in various ways, and, as indicated below, one common strategy was exclusion.

There were so many comments at once. But then I thought about this for a while, that the kind comments became fewer and fewer and the mean comments became more and more common. I felt that I had no obligation to offer space for them. If they wanted to write mean comments about me, I thought that they could start their own blog. 
There appeared to be different types of problematic opponents who were not defined explicitly, but were described as the trolls/haters and "the persistent." The haters and trolls were impolite and sometimes threatening opponents, whereas those who were persistent in their comments were not threatening, but tirelessly wrote very long opposing arguments. The main problem was that trolls/haters and the persistent disturbed the sense of a supportive, sharing community that had been created, to the extent that followers left or were silenced.

People who comment need to think in advance because it scares other people-people who the blog actually addresses-away from commenting or even from reading the blog if there are very long discussions from people who only want to keep us down. Then, people do not dare to comment because they are afraid that these people will attack them verbally.

The engaged citizens therefore stated that exclusion and isolation were necessary in order to keep active followers and comment writers engaged with the blog. As a result, the standards for openness and the inclusion of discussions between opponents promoted by some discussion ideals created difficulties for feminists and antiracist social media debaters.

A second, but less apparent challenge related to the tough media landscape was the low level of patience such as with beginners, which was often discussed in relation to Twitter discussions. This was described as a problem for those who were not as well-read in a field, such as those new to feminism. In this context, there was little room for being uncertain; instead, one had to be very determined and have all the right arguments before writing anything online. Consequently, twitter users had to be confident and choose a firm position; otherwise, a "Twitter mob" could easily attack the them for not having all his or her arguments in line. This need for a high level of knowledge impeded new participants from learning and forming opinions as they discussed and participated. This requirement also risked closing the door to groups of interested people whom the engaged citizens might have been trying to reach.

Strategies for managing difficult discussions and comments can be divided into two approaches. One common approach involved being proactive, and included strategies related to prevention and cooperation; the other approach was more reactive, and included strategies related to moderation, answering/publishing posts, mocking, blocking, or confrontation. The proactive approach involved avoiding trolls by cooperating with other social media debaters in closed groups-such as on Facebook-by sharing information, or laying out explicit rules on one's blog. Another cooperative action involved supporting and encouraging those who received threats and hateful content by reporting criminal or illegal activity to the police or to the owners of the platform. Writing in a style that prevented becoming embroiled in threatening discussions, or disabling the comment feature are examples of approaches that engaged citizens developed after receiving an excessive amount of hateful and abusive comments. The reactive approach was often used in combination with the proactive approach, and the most common tactic was to pre-moderate comments on the blog or other hosted media, such as Facebook groups and pages. Most individuals who pre-moderated content deleted comments that might scare readers and followers away. The persistent and long-winded opponents who seemed to silence other followers in comment 
threads were often managed by providing short answers, or by deleting if they kept writing too many posts. Sexist, racist, or threatening comments were deleted immediately. Problematic and impolite opponents who were not threatening or hateful, however, were not always deleted, but could be managed by providing short answers or counterattacks or by simply ignoring them. Another approach involved cooperating with others within the network to handle the worst cases:

On Twitter, a man wrote a really offensive tweet about rape victims, but many discussed that we could get rid of the Twitter account by reporting him. So many people did it that he was suspended. And on Facebook, when someone writes racist comments in a thread in a group or event, you post a comment in a political group, like "Can someone counter this?" It's like we all mobilize when someone writes something that is totally horrendous.

The Opportunities of Citizen Engagement in Social Media

Figure 3: Subthemes related to the concept of networks

\begin{tabular}{|c|c|c|c|c|c|c|c|}
\hline \multicolumn{8}{|l|}{ Relations } \\
\hline \multicolumn{3}{|c|}{ Values of the network } & \multicolumn{3}{|c|}{ How to build networks } & \multicolumn{2}{|c|}{ Ideas about the network } \\
\hline $\begin{array}{l}\text { Support \& } \\
\text { cooperation }\end{array}$ & $\begin{array}{l}\text { Sense of } \\
\text { community }\end{array}$ & $\begin{array}{l}\text { Spreading } \\
\text { of content }\end{array}$ & $\begin{array}{l}\text { Making } \\
\text { contact }\end{array}$ & $\begin{array}{l}\text { Using } \\
\text { applications }\end{array}$ & $\begin{array}{l}\text { Through } \\
\text { friends }\end{array}$ & Culture & Composition \\
\hline
\end{tabular}

In the analysis, one prominent topic emerged: the role of relations, a type of network in the blogosphere and the social media sphere. These grassroots online writers in this study initially seem to be alone writing and debating in different media, but upon closer examination, they are connected to many others with similar social media use for political purposes. They can be described as part of a loose network of likeminded individuals. Furthermore, these social media debaters were interested in building networks and collaborating online. I also argue that the network has some characteristics of a community that serves certain engaged citizen values. The interviewees' descriptions of their networks related to shared space, practices, identities, support, and the building of interpersonal relationships. Thus, the network that they described seemed to be a prerequisite for success.

The main subtheme values of the network reveals the significance of various online relations. The network, with its community characteristic of a shared support system, was described by many as being highly important to their participation, and described by some as crucial for enduring in this tough part of the online world. The most salient theme here was that of support and cooperation, which included concepts such as pep talks, promotion of others, support in tough debates, support in closed groups, or help with reporting online crime. 
Thus, the easy and instantaneous communicative characteristics of social media that allow for sharing praise and pep talk seemed to offer a very inclusive and supportive context compared with the context of ordinary political party organization as described by some participants. This contradicts what is sometimes claimed about online discussions and forums-that they are spaces in which flaming and bullying are more likely to occur because of the lack of social cues (Baym, 2010, p. 54). Thus, politeness and impoliteness could depend greatly on the norms and culture of the participating individuals and the context. The interviewees' descriptions suggest that it was the specific sense of community (sisterhood, as discussed below) that contributed to developing the culture-as one interviewee described it-of frequent pep talks, praise, and cheering for one another. The benefits of such relations and networks for support were described in different ways. The interviewees stated that they were able to obtain emotional support, backup in discussions with tough opponents, or support in the form of good advice on how to handle misogynists. Having these loosely-bounded relations that were often solely online was an advantage in their otherwise private world of online political engagement. Even simple feedback from other (often feminist) writers was important, and sometimes crucial to enduring in tough political struggles online:

That's what's so fantastic about feminists on the Internet, that they are always so committed and they are always very good at responding so that you know when you've done something wrong or right. It is always present, this sisterhood, such as always commenting on each other's posts. If I publish a fun image or a sad image or anything at all, I always get response such as "Ah, that's fun!" or "Nice!" or "Great that you keep fighting!"

This support was also in evidence when participants collaborated in the face of the hate and threats commonly encountered online. Cooperation with other bloggers was also important, such as writing blog posts together and coordinating and sharing ideas.

In addition, the interviewees' accounts of the benefit and value of relations and networks were also often connected to descriptions of a sense of community. This theme also supports the idea of being part of a network with community characteristics, and the notion that this specific network, with its sense of community, was an important part of their social media engagement. The theme sense of community was expressed with concepts such as sisterhood, belonging, and community, as well as the fact that the group supported one another when expressing opinions. Moreover, relations via online political collaboration developed into friendships for some individuals, even though they had never met in person. Thus, the debaters described a network in which interpersonal relations could develop, and in which the many media that were used in combination offered a sense of togetherness. It was primarily within the sphere of feminist bloggers that this feeling of belonging was mentioned. For example, online misogyny was described as having the positive side effect of strengthening the sense of community among them as they confronted a common challenge. Furthermore, within such network relations, offline meetings such as organized events or meetings for coffee sometimes developed. The sisterhood was also described as a feeling of belonging, and the social media network was described as a way to "get 
ideological input" even if one lived in rural areas where opportunities to find associations and political organizations were scarce.

In my view, female bloggers are better at acknowledging each other. No one else is doing that. If I write something about anti-racism on the blog, I cannot be a hundred percent sure that I'll get backing from other anti-racists. However, if I write something about feminist issues, then I know that most women will enter the conversation and support me.

The spreading of content was also a concept, that emerged from the analysis, with respect to the benefits of relations and networks, referring to a struggle between the desire to be read and become part of the network, and the challenges that online visibility implied. It seems natural to help one another spread content. One interviewee said that top feminist bloggers have an obligation to give back to those who are not yet top feminist bloggers. Using the network for promotion, such as asking closer friends or loose connections on more public platforms such as Twitter to share, link, or retweet content was a common strategy used by these engaged citizens.

When discussing how they build the network, the interviewees' explanations centered on the following themes: making contact, using applications, and through friends. There are different strategies for building networks, and contact is clearly easier to initiate for those who are extroverted and bold. The rather simple comments and likes that the interviewees use have more significance than might be assumed. Relations are often initiated by commenting and linking on blogs, but this type of communication recently seems to have moved to other platforms; today, such initial conversations and contacts often occur on Twitter, Instagram and Facebook groups/pages. For most of these engaged citizens, the network seemed to develop by itself through active online participation and discussion. The use of multiple platforms, particularly Twitter and Facebook, can help in building such a network. A combination of many media is important for building networks and blogging, and having one's own site is useful for developing and promoting longer written texts and being visible in the network. A common approach to building the network involved the need to be active in discussions with interesting people, and to initiate and make contact. Such activity could include short pep talks, discussions, or more genuine inquiries about collaboration. After initial contact through more open and public social media, relations could develop. Furthermore, in terms of network building, some applications were recounted and strategies for combining them such as using blogs with Twitter as a means of making more contacts, or actively participating in Facebook groups. Moreover, having one's own blog or website was important; an individual who had no site of her own might not be noticed by the rest of the sphere, despite being part of the network. A less salient theme involves using friends on social media to be introduced to networks online by tagging or linking into conversations, or by including them in discussions on blogs.

Ideas about the network, besides the themes above regarding the sense of community and support, relate to the interviewees' further descriptions of a culture and the composition of networks. On the theme of Culture concepts such as "high demands," "openness," "same view of the world," and "rhetoric," arose and many indicated that there were high expectations in terms of knowledge for debaters and writers in discussions within 
this largely feminist sphere. Discussions were expected to include appropriate arguments and writing that was not insulting to any minority or oppressed individual. This approach was consistent with the aim of reaching likeminded and well-read individuals within the sphere, but the high demands of debaters could impede new readers and beginners from participating -an audience that the bloggers also sought to reach. The theme of high demands also emerged in the interviewees' accounts of negative experiences and impediments. This contrasts with the value of praise, support, and sisterhood that many described within the networks. In the sphere of likeminded individuals, there was a feeling of sisterhood, which was described as having a very inclusive character. In the feminist, leftist, and anti-racist spheres, tough in-group discussions and critiques occurred, and new bloggers or Twitter users might find it difficult to take part in such activity.

Furthermore, the interviewees described the composition of the networks (their formation and stability) as being loosely bounded, unstable, open, natural, easy to connect to, and interconnected with the offline world. Some described the network as loose and unstable, noting that people came and went within the network, such as in Facebook groups or Twitter. According to the interviewees' descriptions the network seemed to grow in a natural way, and as part of the culture; it was natural and easy to make contact with others in the network. Another aspect that emerged in the analysis regarding network composition, which a collegue and I explored in an article on these engaged citizens specific media use (Larsson \& Olsson, 2016), was that different social media or platforms implied different networks. Thus, different media have different functions in terms of online participation; Twitter is an open, public "safe haven" for political discussion and for making initial contacts, whereas Facebook often houses the most private networks.

\section{Conclusions}

The analysis above answers the research questions by pointing out challenges, opportunities and strategies for the engaged citizes that use blogs and social media. There are limitations to my conclusions, however, due to the selection of and focus on a specific group of engaged citizens. How this group's experiences correspond to those of other groups may be a question for further study.

The identified network was significant in enabling the interviewees' citizen engagement. It had the characteristics of a community in that it offered support, and a sense of community and belonging. The support the network offered in terms of managing abuse can be viewed as something that strengthened it. The political likemindedness also offered, for many interviewees, a shared identity in terms of a feeling of sisterhood or of being part of the same movement. The network was easy to feel included in if one agrees with those views. Thus, their participation was also experienced as being a part of something larger than themselves-a struggle or sisterhood founded via the network, with its community characteristics. Few attempts to engage in discussions with those with conflicting views were made. Instead, the participants cared first and foremost about engaging with likeminded individuals, and therefore excluded those who abused or disrupted.

In relation to the challenges of their engagement, my conclusion is that the primary reason for limiting or adjusting citizen engagement was to manage or avoid abuse. The feminist and anti-racist social media debaters 
experienced the tough climate of debates as problematic, and it could have a silencing effect or lead to them changing the way they used the web. The drawback of visibility was evident, with the interviewees describing a conflict between the desire to be visible to many, and the risk of exposing oneself to hate, threats, and disapproving family members and employers. Although they encountered hate, misogyny, and threats of sexual abuse (cf. Jane, 2014b), these feminists and anti-racists persisted by collaborating and supporting one another. The experiences recounted by these interviewees were similar to those discussed in Herring's 1993 article, in which feminists reported male writers (lengthy and persistent) occupying a large amount of space, and doing so in a style that impeded participation from blog followers. However, the strategies for managing abuse differ. The exclusion strategy was discussed by many interviewees (blocking or excluding abusers) in this study, in contrast to those in the study by Herring et al. (2002). The idea that abuse restrains women online and makes them form their own safe spaces was also proposed by Megarry (2014) and Shaw (2013). The strategy of exposing perpetrators (cf. Megarry, 2014; Vitis \& Gilmour, 2017) seems to be a more recent strategy, furthered by the collaborative and distribution possibilities of social media, but it was not as common in the group interviewed for this article. In reference to Herring et. al. (2002) thoughts on democratic ideals that might steer online behavior, the participants in this study did not fully adhere to the libertarian ideology (cf. Herring 2002 et. al.) that traditionally dominated early Internet culture; instead contemporary exclusion strategies indicate a radical or communitarian culture (Herring et. al., 2002; Hall, 1996). Women and feminists still face the same challenges as in the early days of Internet discussions, but through the network and community features of the available tools (social media, blogs, etc.), strategies such as collaboration and showing support strengthen and protect them from abuse and subsequent withdrawal. Furthermore, the ability to use many platforms and adjust one's identity for each one aids in the management of the negative consequences of visibility, enabling a separation between the political and the private and professional spheres.

Although many of the interviewees described a generous sphere in which one could learn and feel included, there were limits to this inclusion; to be able to endure as an online feminist, anti-racist or leftist political debater, and to enable the participation of the intended audience, they needed to exclude those who threatened to silence them and their readers. Connecting with likeminded individuals in a network that might offer support and opportunities for collaboration was a successful strategy for social media debaters who sought to develop as engaged citizens and manage abuse. Using a variety of strategies to counter abuse, and using actions such as excluding and monitoring abusers, without hesitation and with mutual support, seemed to be an effective way to facilitate long-term participation for this specific group.

\section{References}

Abidin, C. (2013). Cyber-BFFs*: Assessing women's 'perceived interconnectedness' in Singapore's commercial lifestyle blog industry *Best Friends Forever. Global Media Journal: Australian Edition, 71).

Baym, N.K. (2010). Personal connections in the digital age. Cambridge: Polity.

Binns, A. (2012). DON'T FEED THE TROLLS!: Managing troublemakers in magazines' online communities. 
Journalism Practice, 6(4). 547-562.

Boulianne, S. (2015). Social media use and participation: A meta-analysis of current research. Information, Communication \& Society, 18(5), 524-538.

Castells, M. (1996). The information age: economy, society and culture. Vol. 1, The rise of the network society. Malden, MA: Blackwell.

Dahlgren, P. (2011). Parameters of online participation: Conceptualizing civic contingencies. CM-časopisza upravljanje komuniciranjem, 6(21), 87-109.

Gillmor, D. (2004) We the media: Grassroots journalism by the people, for the people, Sebastopol, CA: O'Reilly.

Gumbus, A., \& Meglich, P. (2013). Abusive online conduct: Discrimination and harassment in cyberspace. Journal of Management Policy and Practice, 14(5), 47.

Hagemann, C. (2002). Participation in and Content of Two Dutch Political Party Discussion Lists on the Internet. Javnost-The Public, 9(2).

Hall, K. (1996). Cyberfeminism. In S. C. Herring (ed.), Computer-mediated communication: Linguistic, social and cross-cultural perspectives (147-170). Amsterdam: John Benjamin.

Herring, S. (1993). Gender and democracy in computer-mediated communication. Electronic Journal of Communication, 3(2). Special issue on computer-mediated communication. Retrieved from http://www.cios.org/EJCPUBLIC/003/2/00328.HTML

Herring, S. C. (1994). Politeness in computer culture: Why women thank and men flame. In Cultural performances: Proceedings of the Third Berkeley Women and Language Conference (278-294). Berkeley, CA: Berkeley Women and Language Group.

Herring, S., Johnson, D. A., \& DiBenedetto, T. (1995). This discussion is going too far! In Hall, K. and Bucholtz, M. (eds.), Gender Articulated: Language and the Socially Constructed Self (66-96). New York: Routledge.

Herring, S. C. (1996). Bringing familiar baggage to the new frontier: Gender differences incomputer-mediated communication. In Vitanza, V. (eds.), CyberReader (144-154). Boston: Allyn \& Bacon. Online: Keynote talk (1994), American Library Association. Retrieved from http://cpsr.org/prevsite/cpsr/gender/herring.txt

Herring, S. C. (1999). The rhetorical dynamics of gender harassment on-line. The Information Society, 15(3), 151-167.

Herring, S., Job-Sluder, K., Scheckler, R., \& Barab, S. (2002). Searching for safety online: Managing "trolling" in a feminist forum. The Information Society, 18(5), 371-384.

Jane, E. A. (2015). Flaming? What flaming? The pitfalls and potentials of researching online hostility. Ethics and Information Technology, 171), 65-87.

Jane, E. A. (2014a). "Back to the kitchen, cunt": Speaking the unspeakable about online misogyny. Continuum, 28(4), 558-570.

Jane, E. A. (2014b). "Your a Ugly, Whorish, Slut" - Understanding E-Bile. Feminist Media Studies, 14(4), 531546. 
Johnson, T. J., \& Perlmutter, D. D. (2010). Introduction: The Facebook election. Mass Communication and Society, 13(5), 554-559.

Keller, J. M. (2012). Virtual feminisms. Information, Communication \& Society, 15(3), 429-447.

Kushin, M. J., \& Yamamoto, M. (2010). Did social media really matter? College students' use of online media and political decision making in the 2008 election. Mass Communication and Society, 13(5), 608-630.

Larsson, S., \& Olsson, T. (2016). Everyday online participation: Strategies and practices in a multi-platform media landscape. In Sandvik, K., Thorhauge, A-M., \& Valtysson B. (eds.), The Media and the Mundane (135-150). Göteborg: Nordicom.

Lee, H. (2005). Behavioral strategies for dealing with flaming in an online forum. The Sociological Quarterly, 46(2), 385-403.

Lewis, R., Rowe, M., \& Wiper, C. (2016). Online abuse of feminists as an emerging form of violence against women and girls. British Journal of Criminology, 576), 1462-1481.

Loveland, M. T., \& Popescu, D. (2011). Democracy on the web. Information, Communication \& Society, 14(5), 684-703.

Megarry, J. (2014). Online incivility or sexual harassment? Conceptualising women's experiences in the digital age. Women's Studies International Forum, 47, 46-55.

Mummery, J., \& Rodan, D. (2013). The role of blogging in public deliberation and democracy. Discourse, Context and Media, 2(1), 22-39.

Nielsen, R. K. (2011). Mundane Internet tools, mobilizing practices, and the coproduction of citizenship in political campaigns. New Media \& Society, 13(5), 755-771.

Olsson, T. (2008). For activists, for potential voters, for consumers: Three modes of producing the civic web. Journal of Youth Studies, 11(5), 497-512.

Papacharissi, Z. (2002). The virtual sphere: The Internet as a public sphere. New Media \& Society, 4(1), 9-27.

Ruiz, C., Domingo, D., Mico, J. L., Diaz-Noci, J., Meso, K., \& Masip, P. (2011). Public sphere 2.0? The democratic qualities of citizen debates in online newspapers. International Journal of Press/Politics, 16(4), 463487.

Shaw, F. (2012). The politics of blogs: Theories of discursive activism online. Media International Australia Incorporating Culture and Policy, 142, 41-49.

Shaw, F. (2013). Still "searching for safety online": Collective strategies and discursive resistance to trolling and harassment in a feminist network. Fibreculture Journal, 22, 93-108. Retrieved from http://fibreculturejournal.org/wp-content/pdfs/FCJ-157Frances Shaw.pdf

Towner, T. L. (2013). All political participation is socially networked?: New media and the 2012 election. Social Science Computer Review, 31(5), 527-541.

Vaccari, C. (2008). From the air to the ground: The Internet in the 2004 US presidential campaign. New Media \& Society, 10(4), 647-665. 
Wellman, B., Quan-Haase, A., Boase, J., Chen, W., Hampton, K., Díaz, I., \& Miyata, K. (2003). The social affordances of the Internet for networked individualism. Journal of Computer-Mediated Communication, $8(3)$.

Vitis, L., \& Gilmour, F. (2017). Dick pics on blast: A woman's resistance to online sexual harassment using humour, art and Instagram. Crime, Media, Culture, 13(3), 335-355.

Wojcieszak, M. E., \& Mutz, D. C. (2009). Online groups and political discourse: Do online discussion spaces facilitate exposure to political disagreement? Journal of Communication, 59(1), 40-56.

Zamith, R., \& Lewis, S. C. (2014). From public spaces to public sphere: Rethinking systems for reader comments on online news sites. Digital Journalism, 2(4), 558-574.

Zhou, X., Chan, Y. Y., \& Peng, Z. M. (2008). Deliberativeness of online political discussion: A content analysis of the Guangzhou Daily website. Journalism Studies, $9(5), 759-770$. 